\title{
Social, Clinical and Psychometric Factors Affecting Self-Rated Oral Health, Self-Rated Health and Wellbeing in Adults: A Cross-Sectional Survey
}

\author{
Popie Damaskinos ${ }^{(}$, Charitini Koletsi-Kounari, Helen Mamai-Homata, William Papaioannou \\ Department of Preventive and Community Dentistry, School of Dentistry, National and Kapodistrian University of Athens, \\ Athens, Greece \\ Email: pdamaskinos @dent.uoa.gr
}

How to cite this paper: Damaskinos, P., Koletsi-Kounari, C., Mamai-Homata, H. and Papaioannou, W. (2022) Social, Clinical and Psychometric Factors Affecting Self-Rated Oral Health, Self-Rated Health and Wellbeing in Adults: A Cross-Sectional Survey. Health, 14, 104-124.

https://doi.org/10.4236/health.2022.141009

Received: December 10, 2021

Accepted: January 21, 2022

Published: January 24, 2022

Copyright $\odot 2022$ by author(s) and Scientific Research Publishing Inc. This work is licensed under the Creative Commons Attribution International License (CC BY 4.0).

http://creativecommons.org/licenses/by/4.0/

(c) (i) Open Access

\begin{abstract}
Background: Many studies examined and reported oral and general health inequalities in clinical health, SROH and SRH. Objectives: The study aims to explore the social influences, gradients and predictors of self-rated oral health (SROH) and self-rated health (SRH) and wellbeing in Greek adults. Methods: Cross-sectional study, of men and women, aged 65 years and over $(\mathrm{N}=743)$ in Greece. Descriptive and statistical analyses were performed for dentate and edentulous participants. For the association between socioeconomic exposures and binary outcomes, logistic regression was performed to estimate Odds Ratios and 95\% Confidence Intervals (OR, 95\% CI); levels of association and Cramer's V were applied to calculate associations and p-values. Results: The objective socioeconomic measures, such as household income, education level and last main occupation were significant predictors and determinants of both SROH and self-rated health (SRH). For Satisfaction with life (SWL), there was a diversity in the results analogous to the dental status of the participants. Household income and SSS were predictors of SWL in dentate participants. In the total sample Household income, occupation and SSS, were predictors of SWL, while in edentulous participants only occupation and SSS were statistically significant $(p<0.05)$. Subjective social status was statistically significant for SROH, SRH and SWL $(p<0.01)$. More men than women reported their SROH and SRH as good. Household income and SSS were predictors of SWL, in dentate participants, thus the better the income and the higher the relative social status, the higher feeling of SWL was recorded. Place of residence had significant associations only with SWL. Household income, education, occupation and SSS had significant levels of
\end{abstract}


association with SROH and SRH in dentate participants $(p<0.05)$. Conclusion: There are socioeconomic gradient inequalities in SROH and SRH in Greek adults living in Attica area. Subjective social status is a predictor of SROH, SRH and SWL. The need to prioritize interventions to eliminate disparities and inequalities in oral and general health and wellbeing of elders is evident.

\section{Keywords}

Self-Rated Oral Health, Self-Rated Health, Inequalities, Satisfaction with Life, Subjective Social Status

\section{Introduction}

Self-rating measures of oral and general health encompass not only the physical and mental domains of health but also social aspects and everyday functioning. Thus, in the literature, there is an increasing volume in epidemiological studies based on perceptions of health and wellbeing, oral health-related quality of life (OHRQoL) and global self-rated health. Self-rated health (SRH) is a global measure for recording subjective feelings of health recognized as subjective health that is extensively used in research. It is a simple and an adequate method in which a single question can capture participants' heath status and self-rating their health, from excellent to poor on a four or five-point scale [1]. Many studies have shown that this single item is a predictor of health and mortality [2]-[9]. A systematic review by DeSalvo et al. (2005) [10] of 22 cohort studies found a statistically significant relationship between poor self-rated health and the risk of mortality [10]. Furthermore, Wu et al. (2013) [1] examined the relationship of SRH and objective health in Chinese and reported that the prevalence of all diseases was associated with poorer SRH, thus SRH reflects objective health status and could be a global measure of health status [1]. Analysis of longitudinal data from the European Community Household Panel found income inequalities were negatively related to self-rated health status in the European Union [11].

Inequalities in health were present in studies that examined SRH and socioeconomic factors [12]-[19]. Some studies have used both global SRH and comparative SRH [20]. Self-rated oral health (SROH) and socioeconomic factors have been examined in many studies and countries (based on nationally representative samples or not) with interesting results. Inequalities in SROH have been reported according to income, education and occupation [21] [22] [23] [24] [25], while others examined SROH in terms of only income and education and also found inequalities [26]-[32]. Education alone has been reported to determine reported inequalities in SRH and SROH [15] [33].

Health, in a wide range of views, includes not only bodily and physical health and the presence or absence of disease, but also personal feelings, spiritual and 
psychological well-being [34] [35]. Health includes the ideas of strength, vitality, and spirit; a person is healthy when he or she is free from illness, can properly participate in everyday life or has good physical status and well-being [36]. The need to develop subjective measures of oral health status was first proposed by Cohen and Jago (1976) [37], who reported the lack of data related to the psycho-social impact of oral health problems at that time [37]. Subjective measures and self-ratings of health have been associated with education level, socioeconomic status and ethnicity, and poor SRH was a strong predictor of subsequent mortality, as strong as, or even stronger than, physical measures. [7] [9] [38]. Moreover, psychosocial factors have been found to affect and predict SRH [12] [39] [40]. In social epidemiology, it is essential to use both clinical and subjective measures of health and oral health; individuals' feelings, personal beliefs, and life experience are fundamental to their own perceptions of well-being and self-rating health. The existence of social inequalities that affect health and mortality is well established. Longevity for those at the lower end of the social status ladder is considerably less attainable than for those higher on the ladder. These social class inequalities exist for almost all chronic diseases in industrial countries; similarly, these inequalities are also apparent in oral health. However, there is relatively little research available regarding these issues, using either clinical or subjective measures, in the ageing population of industrialized countries. Ageing populations, chronic diseases and social inequalities are all concerns for all industrial countries.

Social determinants of health produce inequalities and create a graded distribution of diseases across the whole spectrum of society within and among nations [12]. These social determinants are the underlying causes of health inequalities [41]. Studies reveal the existence of a gradient in general and oral health outcomes that is affected by a patient's socioeconomic position in society. Inequality indicates that individuals in poverty have poorer health, while the gradients show that at each lower level of the social hierarchy, individuals have worse health than those directly above them. Thus, the social gradient is not only for the poor and does not relate solely to absolute deprivation or poverty; instead, it is mainly explained by relative socioeconomic position [12] [42] [43] [44] [45] [46]. Individuals with higher SES are exposed to less stress than the individuals with lower SES, which reflects the impact of the socioeconomic hierarchy on health [47].

The principal aim of the present study is to determine whether social influences and gradients are present in relation to the global SROH and SRH of adults. Furthermore, the study aims to investigate how Greek elders self-rate their oral and general health and to determine the influence of socioeconomic status and wellbeing.

\section{Methods}

This cross-sectional study aims to examine the SROH, SRH, SWL and socioeco- 
nomic inequalities and wellbeing of 743 Greek adults (males and females) aged 65 years or older, living in Athens and Piraeus (Attica) and visiting day centers. Details on the methodology, design and clustering sampling method of the study have been described previously [48]. In brief, permission from Day Centers was received, and an advertisement for the study was placed in each Day Center. Prospective participants were enrolled in the study only after indicating that they understood the aim of the study and were able to participate of their own free will. Visits to the day centers were arranged by appointment, either by telephone or personal communication. The clinical examination procedure was standardized in accordance with WHO guidelines [49] for oral health surveys.

\subsection{Outcome Variables}

For the study we used SROH, SRH and satisfaction with life as outcome (dependent) variables, in relation to explanatory variables, education, household income, occupation and subjective social status (SSS).

Self-rated oral health (SROH), was recorded using a 5-point scale. The participants were asked to answer the question "Would you say your oral health is?" Possible answers: excellent, very good, good, fair and poor. For the binary analysis, the answers were merged in two categories: excellent, very good and good were grouped together as good; poor and fair were grouped together as poor.

Self-rated health (SRH), was recorded using a 5 -point scale. The participants were asked to answer the question "Would you say your health is...?" Possible answers: excellent, very good, good, fair and poor. For the binary analysis the answers were merged in two categories: excellent, very good and good were grouped together as good; poor and fair were grouped together as poor.

Satisfaction with life was measured through the Satisfaction with life scale [50], which includes five items: "In most ways my life is close to my ideal"; "The conditions of my life are excellent"; "I am satisfied with my life"; "So far I have gotten the important things I want in life"; and "If I could live my life over and over, I would change almost nothing". The participants answered using the following 7-point scale: strongly disagree, disagree, slightly disagree, neither agree nor disagree, slightly agree, agree, strongly agree. For binary logistic a dummy variable was created based on Diener's explanations for satisfaction with life scale [50]. The top category has $30-35$ (very high score) meaning that they are highly satisfied. The next category is those with scores form 25 - 29 (high scores); the third category is the average score $20-24$. The fourth category is the slightly below average-with scores $15-19$ and those with this range of score that have feelings of dissatisfaction; usually these people have many problems in their everyday life that hardly feel satisfaction. The fifth category has scores $10-14$ (dissatisfied) and these persons are dissatisfied with their lives. The last category has scores from 5 to 9 , and is extremely dissatisfied with their lives. Thus, for the binary analysis, we merged the three lower score groups $(<20)$ and the three higher score groups $(\geq 20)$ as not satisfied vs satisfied. 
Education level, was recorded as the total years of education, as the highest certificate of education received, and as an ISCED-97 classification. For the binary analysis, we used a dichotomous categorization of less than a lower secondary education vs a lower secondary education or higher. This categorization has been used before for other studies in Europe [51].

Income was recorded as personal and household income (euros per month) before taxes. For the analysis, we used the equivalence scale (square root scale) for household income according to OECD. The square root scale household income was merged into four categories: less than 600, between 600 and 799, between 800 and 999, and more than 999 euros per month.

Occupation classification was recorded according to the participant's former main occupation using the International Classification of Occupation [52]. For the analysis the ten groups were merged into four: professionals, service and shop keepers, agriculture and craft workers, and manual workers. For the binary analysis we used the dichotomous categorization of manual workers vs non manual workers.

Subjective social status (SSS) was assessed by the MacArthur social status scale, represented as a ladder with 10 steps. This social status measure was developed by the MacArthur Network on SES and Health to represent and record an individual's perception of their place on the social ladder, which takes into account multiple elements of socioeconomic status and social position [53].

\subsection{Other Variables}

1) Age: All the participants were 65 years old or older. For the binary analysis, two groups were formed: $65-74$ years $(\mathrm{n}=365 ; 49.1 \%)$ and $75-94$ years $(\mathrm{n}=$ 378; 50.9\%). Marital status was recorded using four categories: married, widowed, divorced or separated, and single. For the analysis the variable was recoded into three groups as: married $(\mathrm{n}=318 ; 42.8 \%)$, widowed $(\mathrm{n}=358 ; 48.2 \%)$ and divorced-separated-single $(n=67 ; 9 \%)$, and into the dichotomous variable married vs all others.

2) Oral Hygiene Index Simplified (OHI-S) [54]: The average individual or group debris and calculus scores were combined to produce the simplified Oral Hygiene Index. Oral Health Related Quality of Life (OHRQOL). We used the Oral Impacts on Daily Performance (OIDP) to assess OHRQOL [55] [56]. For the binary analysis we used the dichotomous has impact vs has no impact (answers "yes" or "no" for difficulty with activity that impact affecting their life).

Long-standing illness and long-standing illness limited daily activity were scored dichotomously (yes vs no).

3) Loneliness: was assessed by the UCLA 3-item Loneliness scale. This scale includes three items: "How often do you feel that you lack companionship?"; "How often do you feel left out?" and "How often do you feel isolated from others?". Possible answers are hardly ever, some of the time, and often. For binary analysis, the median was used (score 6). 
Ethical approval for the study was granted by the Ethics Committee of the Dental School, National and Kapodistrian University of Athens (253/27-01-015). All the participants volunteered to participate, and informed consent was obtained from all individual participants included in the study. The ethical considerations of the study were in accordance with the principles of the 1964 Declaration of Helsinki and its later amendments.

\subsection{Data Analysis}

The descriptive analysis included sample demographics and socioeconomic characteristics. Statistical analyses were performed for dentate and/or edentulous participants, as shown in each table. The dependent variables were SROH, SRH and satisfaction with life. For the association between socioeconomic exposures and binary outcomes, we used logistic regression to estimate odds ratios and 95\% confidence intervals (OR, 95\% CIs). Furthermore, levels of association and Cramer's V were applied to calculate associations and p-values. Statistical analysis was performed using the Statistical Package for Social Sciences (SPSS) program, version 24 .

\section{Results}

The results are presented in five tables and additional three tables in the supplementary material: Table 1 , summarizes the sample characteristics and dental status of the participants.

Participants were men and women from Attica, Greece residents of Athens or Peireuas. The prevalent population lived in Athens, were female and widowed. Most of the participants had less than lower secondary education, reported being in the second household income quintile, being plant and machinery operators, with good oral health index, and visited the dentist occasionally or when in trouble (Table 1).

The SROH, SRH, and satisfaction with life of the dentate and edentulous participants are presented in Table 2.

Two hundred and sixty participants (35\%) self-reported their oral health as poor/fair, while two hundred and sixty-nine participants (36.2\%) self-reported their general health as poor/fair. Associations between socioeconomic status predicting SROH and SRH as poor or fair are presented for the whole sample in Table 3. Household income, education, occupation and Subjective Social Status are statistically significant $(p<0.05)$ for both self-rated oral health and self-rated general health.

All regression models were adjusted for age, gender, place of residence, living alone, long-standing illness, long-standing illness limited daily activity and loneliness. Further analysis only for dentate participants revealed associations between socioeconomic status predicting $\mathrm{SROH}$ and $\mathrm{SRH}$ as poor or fair are presented in, Table 4. The results are similar as presented above for the total sample, thus, Household income, education, occupation and Subjective Social Status 
Table 1. Demographic characteristics $(\mathrm{N}=743)$.

\begin{tabular}{|c|c|c|c|c|c|c|c|}
\hline \multirow{2}{*}{\multicolumn{2}{|c|}{ Sample characteristics }} & \multicolumn{2}{|c|}{ Total sample } & \multicolumn{2}{|c|}{ Edentulous } & \multicolumn{2}{|c|}{ Dentate } \\
\hline & & $\mathrm{N}$ & $\%$ & $\mathrm{~N}$ & $\%$ & $\mathrm{~N}$ & $\%$ \\
\hline \multirow{2}{*}{ Gender } & male & 354 & $47.6 \%$ & 123 & $60.3 \%$ & 231 & $42.9 \%$ \\
\hline & female & 389 & $52.4 \%$ & 81 & $39.7 \%$ & 308 & $57.1 \%$ \\
\hline \multirow{2}{*}{$\begin{array}{l}\text { Place of } \\
\text { residence }\end{array}$} & Athens & 528 & $71.1 \%$ & 143 & $70.1 \%$ & 385 & $71.4 \%$ \\
\hline & Piraeus & 215 & $28.9 \%$ & 61 & $29.9 \%$ & 154 & $28.6 \%$ \\
\hline \multirow{2}{*}{$\begin{array}{l}\text { Long standing } \\
\text { illness }\end{array}$} & yes & 148 & $19.9 \%$ & 45 & $22.1 \%$ & 103 & $19.1 \%$ \\
\hline & no & 595 & $80.1 \%$ & 159 & $77.9 \%$ & 436 & $80.9 \%$ \\
\hline \multirow{2}{*}{$\begin{array}{l}\text { Limited daily } \\
\text { activity }\end{array}$} & yes & 99 & $13.3 \%$ & 27 & $13.2 \%$ & 72 & $13.4 \%$ \\
\hline & no & 644 & $86.7 \%$ & 177 & $86.8 \%$ & 467 & $86.6 \%$ \\
\hline \multirow{2}{*}{ Age } & $65-74$ & 365 & $49.1 \%$ & 59 & $28.9 \%$ & 306 & $56.8 \%$ \\
\hline & $75-94$ & 378 & $50.9 \%$ & 145 & $71.1 \%$ & 233 & $43.2 \%$ \\
\hline \multirow{2}{*}{ Living alone } & yes & 336 & $45.2 \%$ & 120 & $58.8 \%$ & 216 & $40.1 \%$ \\
\hline & no & 407 & $54.8 \%$ & 84 & $41.2 \%$ & 323 & $59.9 \%$ \\
\hline \multirow{3}{*}{ Marital status } & married & 318 & $42.8 \%$ & 62 & $30.4 \%$ & 256 & $47.5 \%$ \\
\hline & widowed & 358 & $48.2 \%$ & 135 & $66.2 \%$ & 223 & $41.4 \%$ \\
\hline & other & 67 & $9.0 \%$ & 7 & $3.4 \%$ & 60 & $11.1 \%$ \\
\hline \multirow{4}{*}{$\begin{array}{l}\text { Household } \\
\text { Income } \\
\text { (euro/per } \\
\text { month) }\end{array}$} & $>600$ & 98 & $13.2 \%$ & 34 & $16.7 \%$ & 64 & $11.9 \%$ \\
\hline & 600 to 799 & 212 & $28.5 \%$ & 83 & $40.7 \%$ & 129 & $23.9 \%$ \\
\hline & 800 to 999 & 292 & $39.3 \%$ & 65 & $31.9 \%$ & 227 & $42.1 \%$ \\
\hline & $>999$ & 141 & $19.0 \%$ & 22 & $10.8 \%$ & 119 & $22.1 \%$ \\
\hline \multirow{2}{*}{$\begin{array}{c}\text { Subjective } \\
\text { social } \\
\text { status (SSS) }\end{array}$} & Low steps & 259 & $34.9 \%$ & 102 & $50.0 \%$ & 157 & $29.1 \%$ \\
\hline & $\begin{array}{c}\text { Medium and } \\
\text { High }\end{array}$ & 484 & $65.1 \%$ & 102 & $50.0 \%$ & 382 & $70.9 \%$ \\
\hline \multirow{2}{*}{$\begin{array}{c}\text { Education } \\
\text { level } \\
\text { (ISCED-97) }\end{array}$} & $\begin{array}{c}\text { >Lower } \\
\text { secondary }\end{array}$ & 498 & $67.0 \%$ & 161 & $78.9 \%$ & 337 & $62.5 \%$ \\
\hline & $\begin{array}{c}\text { Lower } \\
\text { secondary or } \\
\text { above }\end{array}$ & 245 & $33.0 \%$ & 43 & $21.1 \%$ & 202 & $37.5 \%$ \\
\hline \multirow{2}{*}{ Occupation } & manual & 600 & $80.8 \%$ & 43 & $21.1 \%$ & 424 & $78.7 \%$ \\
\hline & non manual & 143 & $19.2 \%$ & 28 & $13.7 \%$ & 115 & $21.3 \%$ \\
\hline \multirow[t]{2}{*}{$\begin{array}{c}\text { Reason } \\
\text { dental visits }\end{array}$} & $\begin{array}{c}\text { occasionally } \\
\text { orwhen in } \\
\text { trouble }\end{array}$ & 640 & $86.1 \%$ & 199 & $97.5 \%$ & 441 & $81.8 \%$ \\
\hline & regularly & 103 & $13.9 \%$ & 5 & $2.5 \%$ & 98 & $18.2 \%$ \\
\hline \multirow{3}{*}{$\begin{array}{l}\text { Remaining } \\
\text { teeth }\end{array}$} & has $1-10$ & 135 & $25.0 \%$ & - & - & 135 & $25.0 \%$ \\
\hline & has 11 to 19 & 167 & $31.0 \%$ & - & - & 167 & $31.0 \%$ \\
\hline & has 20 to 31 & 237 & $44.0 \%$ & - & - & 237 & $44.0 \%$ \\
\hline \multirow{2}{*}{ OHRQOL } & has impact & 225 & $30.3 \%$ & 68 & $33.3 \%$ & 157 & $29.1 \%$ \\
\hline & no impact & 518 & $69.7 \%$ & 136 & $66.7 \%$ & 382 & $70.9 \%$ \\
\hline
\end{tabular}


Table 2. Self-Rated oral health, self-rated health, and satisfaction with life in dentate and edentulous participants $(\mathrm{N}=743)$.

\begin{tabular}{|c|c|c|c|c|c|c|c|}
\hline & & \multicolumn{2}{|c|}{ SROH Poor N (\%) } & \multicolumn{2}{|c|}{ SRH Poor N (\%) } & \multicolumn{2}{|c|}{ SWL low N (\%) } \\
\hline & & Edentulous & Dentate & Edentulous & Dentate & Edentulous & Dentate \\
\hline Gender & male & $45(68.2 \%)$ & $76(39.2 \%)$ & $42(50.6 \%)$ & $68(36.6 \%)$ & $51(67.1 \%)$ & $72(49.0 \%)$ \\
\hline Place of residence & Athens & $49(74.2 \%)$ & $134(69.1 \%)$ & $63(75.9 \%)$ & $136(73.1 \%)$ & $43(56.6 \%)$ & $87(59.2 \%)$ \\
\hline $\begin{array}{c}\text { Long } \\
\text { standing illness }\end{array}$ & yes & $21(31.8 \%)$ & $49(25.3 \%)$ & $34(41.0 \%)$ & $64(34.4 \%)$ & $19(25.0 \%)$ & $43(29.3 \%)$ \\
\hline $\begin{array}{c}\text { Limited } \\
\text { daily activity }\end{array}$ & yes & $16(24.2 \%)$ & $36(18.6 \%)$ & $22(26.5 \%)$ & $52(28.0 \%)$ & $14(18.4 \%)$ & $25(17.0 \%)$ \\
\hline Age & $65-74$ & $19(28.8 \%)$ & $109(56.2 \%)$ & $31(37.3 \%)$ & 105 (56.5\%) & $16(21.1 \%)$ & $69(46.9 \%)$ \\
\hline \multirow[t]{2}{*}{ Living alone } & yes & $37(56.1 \%)$ & $87(44.8 \%)$ & $47(56.6 \%)$ & $76(40.9 \%)$ & $51(67.1 \%)$ & $63(42.9 \%)$ \\
\hline & married & $21(31.8 \%)$ & $85(43.8 \%)$ & $29(34.9 \%)$ & $80(43.0 \%)$ & $19(25.0 \%)$ & $69(46.9 \%)$ \\
\hline \multirow[t]{3}{*}{ Marital status } & widowed & $42(63.6 \%)$ & $88(45.4 \%)$ & $48(57.8 \%)$ & $84(45.2 \%)$ & $56(73.7 \%)$ & $59(40.1 \%)$ \\
\hline & Single/divorced & $3(4.5 \%)$ & $21(10.8 \%)$ & $6(7.2 \%)$ & $22(11.8 \%)$ & $1(1.3 \%)$ & $19(12.9 \%)$ \\
\hline & $>600$ & $14(21.2 \%)$ & $31(16.0 \%)$ & $16(19.3 \%)$ & $29(15.6 \%)$ & $11(14.5 \%)$ & $24(16.3 \%)$ \\
\hline \multirow{3}{*}{$\begin{array}{c}\text { Household } \\
\text { Income } \\
\text { (euro/per month) }\end{array}$} & 600 to 799 & $26(39.4 \%)$ & $57(29.4 \%)$ & $26(31.3 \%)$ & $58(31.2 \%)$ & $40(52.6 \%)$ & $40(27.2 \%)$ \\
\hline & 800 to 999 & $22(33.3 \%)$ & $74(38.1 \%)$ & $30(36.1 \%)$ & $66(35.5 \%)$ & $20(26.3 \%)$ & $50(34.0 \%)$ \\
\hline & $>999$ & $4(6.1 \%)$ & $32(16.5 \%)$ & $11(13.3 \%)$ & $33(17.7 \%)$ & $5(6.6 \%)$ & $33(22.4 \%)$ \\
\hline $\begin{array}{c}\text { Subjective social } \\
\text { status }\end{array}$ & Low steps $(1-4)$ & $43(65.2 \%)$ & $75(38.7 \%)$ & $48(57.8 \%)$ & $73(39.2 \%)$ & $59(40.1 \%)$ & $53(69.7 \%)$ \\
\hline Education level & $>$ lower secondary & $57(86.4 \%)$ & $143(73.7 \%)$ & $66(79.5 \%)$ & $133(71.5 \%)$ & $93(63.3 \%)$ & $67(88.2 \%)$ \\
\hline \multirow{2}{*}{ Occupation } & manual & $58(87.9 \%)$ & $166(85.6 \%)$ & $73(88.0 \%)$ & $156(83.9 \%)$ & $120(81.6 \%)$ & $74(97.4 \%)$ \\
\hline & non manual & $8(12.1 \%)$ & $28(14.4 \%)$ & $10(12.0 \%)$ & $30(16.1 \%)$ & $27(18.4 \%)$ & $2(2.6 \%)$ \\
\hline \multirow{2}{*}{$\begin{array}{c}\text { Reason } \\
\text { dental visits }\end{array}$} & $\begin{array}{c}\text { occasionally/when } \\
\text { in trouble }\end{array}$ & $65(98.5 \%)$ & $164(84.5 \%)$ & $80(96.4 \%)$ & $155(83.3 \%)$ & $127(86.4 \%)$ & $74(97.4 \%)$ \\
\hline & regularly & $1(1.5 \%)$ & $30(15.5 \%)$ & $3(3.6 \%)$ & $31(16.7 \%)$ & $20(13.6 \%)$ & $2(2.6 \%)$ \\
\hline \multirow{3}{*}{$\begin{array}{l}\text { Remaining teeth } \\
\text { (dentate) }\end{array}$} & has $1-10$ & - & $65(33.5 \%)$ & - & $65(34.9 \%)$ & - & $48(32.7 \%)$ \\
\hline & has 11 to 19 & - & $62(32.0 \%)$ & - & $46(24.7 \%)$ & - & $41(27.9 \%)$ \\
\hline & has 20 to 31 & - & $67(34.5 \%)$ & - & $75(40.3 \%)$ & - & $58(39.5 \%)$ \\
\hline \multirow{2}{*}{ OHRQOL } & has impact & $34(51.5 \%)$ & $95(49.0 \%)$ & $35(42.2 \%)$ & $66(35.5 \%)$ & $47(32.0 \%)$ & $27(35.5 \%)$ \\
\hline & no impact & $32(48.5 \%)$ & $99(51.0 \%)$ & $48(57.8 \%)$ & $120(64.5 \%)$ & $100(68.0 \%)$ & 49 (64.5\%) \\
\hline
\end{tabular}

are statistically significant $(p<0.05)$ for both self-rated oral health and self-rated general health (Table 4).

Summary models for socioeconomic factors and SSS, SROH, SRH and the results of logistic regression models for SROH, SRH for each socioeconomic variable are shown in Table 5. Household income, education level and occupation were predictors and determinants of both SROH and SRH. Education was not a predictor of SWL in dentate and in all participants. Moreover, occupation was not a predictor of satisfaction with life in dentate participants though it was a 
Table 3. Associations between objective socioeconomic factors and subjective social status predicting SROH and SRH as poor or fair in the total sample, $\mathrm{N}=743$.

\begin{tabular}{|c|c|c|c|c|c|c|c|c|}
\hline \multicolumn{9}{|c|}{ All Participants $N=743$} \\
\hline \multirow[b]{2}{*}{ Models } & \multicolumn{4}{|c|}{$\mathrm{SROH}$} & \multicolumn{4}{|c|}{ SRH } \\
\hline & $\mathrm{B}$ & OR & $95 \% \mathrm{CI}$ & $P$ & B & OR & $95 \% \mathrm{CI}$ & $P$ \\
\hline $\begin{array}{l}\text { Household income } \\
<800 \text { euro per month }\end{array}$ & -0.489 & 0.613 & $0.427-0.882$ & $0.008^{\star *}$ & -0.391 & 0.676 & $0.463-0.988$ & $0.043^{\star}$ \\
\hline $\begin{array}{l}\text { Education level ISCED-97 } \\
\text { (less than lower secondary) }\end{array}$ & -0.731 & 0.482 & $0.337-0.688$ & $<0.001^{\star * *}$ & -0.433 & 0.649 & $0.452-0.931$ & $0.019^{* *}$ \\
\hline Occupation (manual) & -0.557 & 0.573 & $0.377-0.870$ & $0.009^{* *}$ & -0.468 & 0.626 & $0.408-0.961$ & $0.032^{*}$ \\
\hline SSS (low steps $1-4$ ) & -0.653 & 0.520 & $0.377-0.718$ & $<0.001^{\star * *}$ & -0.657 & 0.519 & $0.370-0.728$ & $<0.001^{\star * *}$ \\
\hline
\end{tabular}

${ }^{\star} p<0.05,{ }^{* *} p<0.01,{ }^{* *} p<0.001$. Models adjusted for: age, gender, place of residence, living alone, long-standing illness, long-standing illness limited daily activity and loneliness.

Table 4. Associations between objective socioeconomic factors and subjective social status predicting SROH and SRH as poor or fair, in dentate participants, $\mathrm{n}=539$.

\begin{tabular}{ccccccccc}
\hline \multicolumn{7}{c}{ All Participants N $=539$} \\
\hline \\
\hline Models & B & OR & $95 \%$ CI & $p$ & B & OR & $95 \%$ CI & $p$ \\
\hline $\begin{array}{c}\text { Household income } \\
<80 \text { euro per month }\end{array}$ & -0.584 & 0.558 & $0.361-0.861$ & $0.008^{* *}$ & -0.806 & 0.447 & $0.280-0.713$ & $0.001^{* *}$ \\
$\begin{array}{c}\text { Education level ISCED-97 } \\
\text { (less than lower secondary) }\end{array}$ & -0.731 & 0.482 & $0.337-0.688$ & $<0.001^{* * *}$ & -0.433 & 0.649 & $0.452-0.931$ & $0.019^{* *}$ \\
$\begin{array}{c}\text { Occupation (manual) } \\
\text { SSS (low steps 1-4) }\end{array}$ & -0.685 & 0.504 & $0.314-0.810$ & $0.005^{* *}$ & -0.490 & 0.613 & $0.376-0.998$ & $0.049^{*}$ \\
\hline
\end{tabular}

${ }^{\star} p<0.05,{ }^{\star *} p<0.01,{ }^{* *} p<0.001$. Models adjusted for: age, gender, place of residence, living alone, long-standing illness, long-standing illness limited daily activity and loneliness. Education $=$ less than lower secondary education vs lower secondary or above. Occupation $=$ manual workers vs non manual. Subjective social status $=$ low steps $(1-4)$.

Table 5. Predictors for Satisfaction with life in dentate participants and in all participants $N=743$.

\begin{tabular}{|c|c|c|c|c|c|c|}
\hline \multirow[b]{2}{*}{ Models } & \multicolumn{2}{|c|}{ Dentate Participants $n=539$} & \multicolumn{2}{|c|}{ All Participants $\mathrm{N}=743$} & \multicolumn{2}{|c|}{ Edentulous Participants $n=204$} \\
\hline & O R $(95 \% \mathrm{CI})$ & $p$ & OR $(95 \% \mathrm{CI})$ & $p$ & OR $(95 \% \mathrm{CI})$ & $p$ \\
\hline $\begin{array}{l}\text { Household income } \\
<800 \text { euro per month }\end{array}$ & $0.565(0.348-0.919)$ & $0.021^{*}$ & $0.584(0.396-0.860)$ & $0.007^{\star *}$ & $0.672(0.324-1.353)$ & ns \\
\hline $\begin{array}{c}\text { Education ISCED-97 } \\
\text { less than lower } \\
\text { secondary }\end{array}$ & $0.842(0.545-1.301)$ & ns & $0.702(0.484-1.017)$ & ns & $0.461(0.199-1.068)$ & ns \\
\hline $\begin{array}{c}\text { Occupation } \\
\text { (manual workers) }\end{array}$ & $0.731(0.442-1.208)$ & ns & $0.531(0.335-0.841)$ & $0.007^{\star * *}$ & $0.110(0.025-0.495)$ & $0.004^{*}$ \\
\hline Subjective social status & $0.454(0.296-0.698)$ & $<0.001^{* * *}$ & $0.401(0.284-0.567)$ & $<0.001^{\star * *}$ & $0.328(0.171-0.627)$ & $0.001^{* *}$ \\
\hline
\end{tabular}

${ }^{\star} p<0.05,{ }^{* *} p<0.01,{ }^{* *} p<0.001$. Models adjusted for: age, gender, place of residence, living alone, long standing illness, limited daily activity and loneliness. ns: no significant differences. 
significant predictor of satisfaction with life in all participants and in edentulous (with no teeth) (Table 5). All regression models were adjusted for age, gender, place of residence, living alone, long standing illness, limited daily activity and loneliness, and the Omnibus Tests of Model Coefficients sig was less than 0.05, and the Hosmer and Lemeshow test's significant values were greater than 0.05 .

Household income and SSS were predictors and determinants of SWL in dentate participants while in the total sample Household income, occupation and SSS were predictors of SWL $(p<0.05)$. For those being edentulous only occupation and SSS were statistically significant $(p<0.05)$ and predictors of SWL (Table 5).

Logistic regression analysis results for edentulous participants revealed only education ( $\mathrm{p}=0.04)$ and SSS ( $\mathrm{p}=0.004)$ as predictors of SROH; and only SSS ( $\mathrm{p}=$ 0.043 ) was a predictor of SRH in participants with no teeth (results not shown). Further analysis of other predictors and the effect of household income, education, occupation and SSS on SROH, SRH and SWL are presented in the supplementary material (Supplementary Tables S1-S3).

Long-standing illness, long-standing illness limiting daily activity, and the number of remaining teeth had significant levels of association for all three outcomes, in the total sample. Place of residence had significant associations only with SWL; those living in Athens had higher scores of SWL (Supplementary Table S1). Household income, education, occupation and Subjective Social Status had significant levels of association with $\mathrm{SROH}$ in the total sample and in dentate participants $(p<0.05)$ (Supplementary Table S2 and Table S3). The results of regression analysis for the total sample and the dentate participants showed that Household income, education, and SSS were predictors of SRH $(p<0.05)$ while occupation was not a predictor of SRH in the total sample and in dentate participants. These regression models were adjusted not only for age, gender, place of residence, living alone, long-standing illness, long-standing illness limited daily activity, and loneliness but also for satisfaction with life (Supplementary Table S2 and Table S3).

\section{Discussion}

In this study, we examined socioeconomic, clinical and psychometric factors affecting SROH, SRH and satisfaction with life (SWL) in adults aged 65 years and over. The study showed the association between household income, education level, occupation and clinical measures of health, and SROH and SRH in Greeks living independently in Attica. All three objective socioeconomic measures (household income, education, and occupation) used in the study were predictors of SROH in the total sample and in dentate participants $(p<0.01)$ while Household income and education were predictors of SRH in the total sample and the dentate participants $(p<0.05)$. The subjective socioeconomic measure SSS was also found to predict SROH, SRH and SWL; while SSS predicted SWL levels, education and occupation were not predictors of SWL, in dentate partici- 
pants. Income and education were not predictors of satisfaction with life in edentulous participants. Thus, dental status of the participants and the number of remaining teeth influenced the overall results.

Gender, place of residence, long standing illness, SSS and loneliness were predictors of SWL. Men who lived in Athens with no long-standing illness, and placed themselves as standing on higher steps of the MacArthur social status scale and felt less lonely, were more likely to report being more satisfied with life (SWL). Thus, relative social status and psychosocial factors are associated and impact perceptions of wellness. Moreover, the results of the current study highlight the effect of remaining teeth in discernments of SROH and SRH. Place of residence was statistically significant and had an impact on perceptions of wellbeing and SWL, while levels of associations of OHRQOL were statistically significant only for SROH and SRH but not for SWL.

The analysis revealed the presence of health inequalities in SROH and SRH. Socioeconomic factors impacted consciousness and judgment of health and showed inequalities, educational, income and occupation gradients. Inequalities and the social gradient in clinical and subjective oral health were reported for Greek elders in a preliminary analysis of data [15]. To the best of or knowledge this is the first study to explore and found socioeconomic inequalities and the gradient in SROH in Greeks; the first study that examined oral health and SSS in Greece and the first study to examine SRH and socioeconomic inequalities using both objective and subjective socioeconomic measures and found gradient inequalities in Greek adults. Other studies in Greek adults examined SRH but used either a subjective or an objective socioeconomic measure and are discussed below. Self-rated general health and the presence of a gradient among Greek adults were reported by Theodosiou and Zingelides in 2009 [57]. A recent study in Greek adults examined SRH and SSS and found that age and the presence of a chronic disease affects SRH and that the higher the perceived SSS, the higher the odds of reporting very good SRH [58]. A study that examined SRH, socioeconomic status (objective measures) and indebtedness in Greek adults found that males and younger individuals with higher SES had a higher probability of reporting better SRH [14], which is in agreement with the results of the present study. The results of Daniilidou and co-workers [59] in a study of Greek adults (aged 18 and over), found that SRH was influenced by income, education, age and gender, however variables such as physical activity and psychometric factors were not used in that study [59]. In our study, there was no significant relationship between age and SRH; however, gender was significantly associated with SRH and SROH and women were more likely to report their SROH and SRH as poor. Long standing illness and long-standing illness that limited daily activity were significantly associated with SRH in the present study; those who reported having a long-standing illness that limited their daily activity were more likely to rate their SROH and SRH as poor and had lower levels of satisfaction with life. Those in the age group 65 - 74 years old were more possible to report good oral 
health and more satisfied with life than those in the age group 75 - 94 years old. There was a gender effect for SROH and SRH; more men reported good SROH and SRH, than women, while there was no effect of place of residence. Those with the higher income, higher education level, with better jobs and higher SSS were more likely to rate their SROH and SRH as good and enjoy a higher level of satisfaction with life. These results are in accordance with previous studies worldwide that revealed socioeconomic inequalities in health, thus income, education and occupation were determinants of SROH [60]-[66], SRH [67] [68] [69] [70] and mortality [4] [71] [72]. Moreover, Song and co-workers [73], reported that various diseases and healthy lifestyles and socioeconomic status were determinants of SRH in Chinese adults. Thus, low to moderate alcohol consumption and physical activity were associated with good SRH. Likewise, higher socioeconomic status was associated with good SRH [73].

Olaf von dem Knesebeck and co-workers [51], used data from the European Social Survey 2003 where they examined education and SRH in 22 European countries, including Greece. Their results for SRH (less than good) were 22.8\% for men and $34.4 \%$ for women in Greek adults are varying from the present study's results where $31.1 \%$ of men and $40.9 \%$ of women reported SRH less than good. The differences are possibly due to the sample procedures and methodology (inclusion criteria) as the present study included participants only from Attica and were 65 - 94 years old, while the European Society Survey had participants from all areas of Greece and were 25 years or older.

The results of the European Project "Enabling Autonomy, Participation, and Well-Being in Older Age: The Home Environment as a Determinant for Healthy Ageing" based on Latvian and Swedish data showed that poor perceived mobility was associated with poor SRH, while education was a determinant of SRH only for the Latvian. Age was not a significant determinant for either population [76]. Our results showed that for dentate participants' age was significantly associated with SROH and SWL $(\mathrm{p}=0.001)$, however, the findings for SRH were not significant, in accordance with the Latvian and Swedish data, as reported by Harschel et al., 2015 [74]. In the present study, education, income and occupation were statistically significant with both SROH and SRH $(\mathrm{p}=0.01)$ and better $\mathrm{SROH}$ and SRH were associated with higher socioeconomic status.

Income inequalities in self-rated health were also reported in Japan; at the prefecture level, the association between income and SRH was especially strong [75]. In a cross-sectional study in Russia, education, material deprivation and perceived control were related to SRH [76]. In the present study, SRH (poor vs good), was also predicted by education, occupation ( $p<0.05)$, SSS $(\mathrm{p}<0.001)$ and household income less than 800 euros per month $(\mathrm{p}<0.01)$. Mejia and co-workers [77], examined $\mathrm{SROH}$ and social inequality among Australians (Australia's National Survey of Adult Oral Health, 2004-2006) and found that those who reported an annual income less than 20,000 Aus. \$ and those who were less educated or unemployed were more likely to report poor oral health; 
this finding is in accordance with our results; in the present study poor SROH was associated with lower income, lower level of education, manual workers and lower subjective social status ( $<<0.05)$. However, an income of 20,000 Aus. \$ ( 12.482 euro) is much higher than 800 euros per month (approximately about 9600 euros per year; 1 Australian Dollar equals 0.62 Euro), and Greece is a country in economic recession with reduced pensions and salaries because of the Memorandum.

A more recent study in Australia reported no associations between poor $\mathrm{SROH}$ and income inequality in Local Government Areas (LGAs) among Australians [78]. However, the present study's results are in agreement with a study from Sweden; socioeconomic measures were strongly associated with $\mathrm{SROH}$ (OR 1.76) and SRH (OR 3.95) in Swedish adults; these results remained significant after controlling for age (mean age 53.4 years), gender and lifestyle variables [79]. Another cross-sectional study had similar results with the present study's results and found socioeconomic gradients in dental health among adults 30-64 years old, in Spain (data from the 2006 Spanish National Health Survey); there were significant socioeconomic differences according to education, household income and occupation, in the spreading of self-reported dental problems among middle-age adults [21]. The present study's results are in agreement with the results of Jayasvasti and co-workers, in a cross-sectional study about SROH status in Myanmar. They found that tooth loss, less frequent dental care attendance and lower education were associated with poor SROH [80].

Additionally, in our study, participants with no teeth (edentulous) were more likely to report poor or fair SROH, poor or fair SRH and low scores of SWL. This is in line with the results of Barboza-Solis and co-workers [81], who reported that participants with severe tooth loss reported poor SRH. Furthermore, our results are in agreement with Farmer and co-workers results regarding education and income; the study took place in Canada; SROH was examined using a nationally representative Canadian survey, and poor SROH was found to be inversely related to education and income and both socioeconomic measures were evenly balanced with the gradients [82]. In the present study, the participants were 65 years old or older ( 65 to 94 years) and we found that those in the 75 to 94-year-old group had significant inequalities compared to the group of 65 to 74-years-old. A study in England, Wales and Northern Ireland found oral health inequalities in UK adult population with a tendency to diminish with age; for those aged 65 years and over, these inequalities were not statistically significant [83]. In contrast, our results showed that inequalities do not fade with age in the examined population. In the literature, there is conflicting evidence regarding whether socioeconomic inequalities in health diminish or persist in older age [84] [85] [86].

\section{Limitations}

The study has some limitations because of its design. This is a cross sectional 
study with an observational study design in which the outcome and exposures are examined at the same time, which makes causal relationships difficult to conclude; thus, the results should be treated with caution. However, not only cross-sectional studies but longitudinal studies also have confirmed the existence of socioeconomic inequalities and the gradient in health and oral health in many countries; moreover, the results of longitudinal studies found causal associations of SRH and socioeconomic measures [87]. Furthermore, the strengths of the study are the use of multilevel sampling procedures, stratified and clustering methods according to postal codes, area of residence and day centers; the participants were elders aged 65 to 94 years (males and females); both clinical and subjective measures were used, and psychometric factors were also considered. This cross-sectional study can be used as a baseline for a future national cohort study.

\section{Conclusions}

The present study's results confirmed the presence of socioeconomic influences on SROH and SRH in the examined Greek adults. The study examined the effect of objective and subjective socioeconomic measures and found self-rated oral and general health gradient inequalities in Greek adults. Socioeconomic inequalities and the gradient affect SROH and SRH and wellbeing. Income, education level, last main occupation and SSS were predictors of SROH and SRH in dentate participants and the total sample, and the better the income and the higher the relative social status, the higher sensation of SWL was recorded.

Further research needed to explore inequalities and determinants of health and oral health and wellbeing in adults and factors that contribute to preserve more healthy teeth in the mouth in older ages and erase social inequalities. The use of a simple question as a proxy for self-rated oral health and self-rated health is costly effective and a useful screening instrument for epidemiologists and health care workers, especially when resources are limited. Policy makers, health planning and welfare should focus on methods and strategies aiming to eliminate social inequalities and health disparities in oral and general health, aiming to equity and fairness.

\section{Declaration of Conflicting of Interests}

The authors declare no conflict of interest.

\section{References}

[1] Wu, S.Q., Wang, R., Zhao, Y.F., Ma, X.Q., Wu, M.J., Yan, X.Y. and He, J. (2013) The Relationship between Self-Rated Health and Objective Health Status: A Population-Based Study. BMC Public Health, 13, Article No. 320. https://doi.org/10.1186/1471-2458-13-320

[2] Sargent-Cox, K.A., Anstey, K.J. and Luszcz, M.A. (2010) The Choice of Self-Rated Health Measures Matter When Predicting Mortality: Evidence from 10 Years Follow-Up of the Australian Longitudinal Study of Ageing. BMC Geriatrics, 10, Article No. 18. https://doi.org/10.1186/1471-2318-10-18 
[3] Benyamini, Y., Leventhal, H. and Leventhal, E.A. (2004) Self-Rated Oral Health as an Independent Predictor of Self-Rated General Health, Self-Esteem and Life Satisfaction. Social Science \& Medicine, 59, 1109-1116. https://doi.org/10.1016/j.socscimed.2003.12.021

[4] Benjamins, M.R., Hummer, R.A., Eberstein, I.W. and Nam, C.B. (2004) Self-Reported Health and Adult Mortality Risk: An Analysis of Cause-Specific Mortality. Social Science \& Medicine, 59, 1297-1306. https://doi.org/10.1016/j.socscimed.2003.01.001

[5] McGee, D.L., Liao, Y.L., Cao, G.C. and Cooper R.S. (1999) Self-Reported Health Status and Mortality in a Multiethnic US Cohort. American Journal of Epidemiology, 149, 41-46. https://doi.org/10.1093/oxfordjournals.aje.a009725

[6] Benyamini, Y. and Idler, E.L. (1999) Community Studies Reporting Association between Self-Rated Health and Mortality: Additional Studies, 1995 to 1998. Research on Aging, 21, 392-401. https://doi.org/10.1177/0164027599213002

[7] Idler, E.L. and Benyamini, Y. (1997) Self-Rated Health and Mortality: A Review of Twenty-Seven Community Studies. Journal of Health and Social Behavior, 38, 21 37. https://doi.org/10.2307/2955359

[8] Matthias, R.E., Atchison, K.A., Lubben, J.E., Jong, F.D. and Schweitze, S.O. (1995) Factors Affecting Self-Ratings of Oral Health. Journal of Public Health Dentistry, 55, 197-204. https://doi.org/10.1111/j.1752-7325.1995.tb02370.x

[9] Mossey, M. and Shapiro, E. (1982) Self-Rated Health: A Predictor of Mortality among the Elderly. American Journal of Public Health, 72, 800-808. https://doi.org/10.2105/AJPH.72.8.800

[10] Desalvo, K.B., Bloser, N., Reynolds, K., He, J. and Muntner, P. (2006) Mortality Prediction with a Single General Self-Rated Health Question. Journal of General Internal Medicine, 21, Article No. 267. https://doi.org/10.1111/j.1525-1497.2005.00291.x

[11] Hildebrand, V. and Van Kerm, P. (2009) Income Inequality and Self-Rated Health Status: Evidence from the European Community Household Panel. Demography, 46, 805-825. https://doi.org/10.1353/dem.0.0071

[12] Damaskinos, P. (2020) Exploring the Impact of Complex Socioeconomic, Psychometric and Behavioural Factors and the Social Gradient Concerning Clinical and Subjective Measures of Oral Health, in Greek Older Adults. Ph.D. Dissertation, National and Kapodistrian University of Athens, Athens.

[13] Moor, I., Spallek, J. and Richter, M. (2017) Explaining Socioeconomic Inequalities in Self-Rated Health: A Systematic Review of the Relative Contribution of Material, Psychosocial and Behavioural Factors. Journal of Epidemiology \& Community Health, 71, 565-575. https://doi.org/10.1136/jech-2016-207589

[14] Kyriopoulos, I.I., Zavras, D., Charonis, A., Athanasakis, K., Pavi, E. and Kyriopoulos, J. (2016) Indebtedness, Socioeconomic Status, and Self-Rated Health: Empirical Evidence from Greece. Poverty \& Public Policy, 8, 387-397.

https://doi.org/10.1002/pop4.160

[15] Damaskinos, P., Koletsi-Kounari, H., Mamai-Homata, H. and Papaioannou, W. (2014) The Social Gradient in Oral Health in Greek Older Adults. Proceedings Conference, IADR/ PER Congress, Dubrovnik, 10-13 September 2014, 139.

[16] Alvarez-Galvez, J., Rodero-Cosano, M., Motrico, E., Salinas-Perez, J., Garcia-Alonso, C. and Salvador-Carulla, L. (2013) The Impact of Socio-Economic Status on SelfRated Health: Study of 29 Countries Using European Social Surveys (2002-2008). International Journal of Environmental Research and Public Health, 10, 747-761. https://doi.org/10.3390/ijerph10030747 
[17] Dowd, J.B. and Zajacova, A. (2010) Does Self-Rated Health Mean the Same Thing Across Socioeconomic Groups? Evidence from Biomarker Data. Annals of Epidemiology, 20, 743-749. https://doi.org/10.1016/j.annepidem.2010.06.007

[18] Subramanian, S.V., Subramanyam, M.A., Selvaraj, S. and Kawachi, I. (2009) Are Self-Reports of Health and Morbidities in Developing Countries Misleading? Evidence from India. Social Science \& Medicine, 68, 260-265. https://doi.org/10.1016/j.socscimed.2008.10.017

[19] Franks, P., Gold, M.R. and Fiscella, K. (2003) Sociodemographics, Self-Rated Health, and Mortality in the US. Social Science \& Medicine, 56, 2505-2514. https://doi.org/10.1016/S0277-9536(02)00281-2

[20] Vuorisalmi, M., Pietilä, I., Pohjolainen, P. and Jylhä, M. (2008) Comparison of SelfRated Health in Older People of St. Petersburg, Russia, and Tampere, Finland: How Sensitive Is SRH to Cross-Cultural Factors? European Journal of Ageing, 5, Article No. 327. https://doi.org/10.1007/s10433-008-0093-5

[21] Capurro, D.A. and Davidsen, M. (2017) Socioeconomic Inequalities in Dental Health among Middle-Aged Adults and the Role of Behavioral and Psychosocial Factors: Evidence from the Spanish National Health Survey. International Journal for Equity in Health, 16, Article No. 34. https://doi.org/10.1186/s12939-017-0529-7

[22] Tsakos, G., Demakakos, P., Breeze, E. and Watt, R.G. (2011) Social Gradients in Oral Health in Older Adults: Findings from the English Longitudinal Survey of Aging. American Journal of Public Health, 101, 1892-1899. https://doi.org/10.2105/AJPH.2011.300215

[23] Sanders, A.E. and Spencer, A.J. (2004) Social Inequality: Social Inequality in Perceived Oral Health among Adults in Australia. Australian and New Zealand. Australian and New Zealand Journal of Public Health, 28, 159-166. https://doi.org/10.1111/j.1467-842X.2004.tb00930.x

[24] Sanders, A.E. and Spencer, A.J. (2005) Why Do Poor Adults Rate Their Oral Health Poorly? Australian Dental Journal, 50, 161-167. https://doi.org/10.1111/j.1834-7819.2005.tb00355.x

[25] Stahlnacke, K., Soderfeldt, B., Unell, L., Halling, A. and Axtelius, B. (2003) Perceived Oral Health: Changes over 5 Years in One Swedish Age-Cohort. Community Dentistry and Oral Epidemiology, 31, 292-299. https://doi.org/10.1034/j.1600-0528.2003.00008.x

[26] Mejia, G.C., Elani, H.W., Harper, S., Murray Thomson, W., Ju, X., Kawachi, I., Kaufman, J.S. and Jamieson, L.M. (2018) Socioeconomic Status, Oral Health and Dental Disease in Australia, Canada, New Zealand and the United States. BMC Oral Health, 18, Article No. 176. https://doi.org/10.1186/s12903-018-0630-3

[27] Shen, J. and Listl, S. (2018) Investigating Social Inequalities in Older Adults' Dentition and the Role of Dental Service Use in 14 European Countries. The European Journal of Health Economics, 19, 45-57. https://doi.org/10.1007/s10198-016-0866-2

[28] Duijster, D., Oude Groeniger, J., Van Der Heijden, G.J.M.G. and Van Lenthe, F.J. (2018) Material, Behavioural, Cultural and Psychosocial Factors in the Explanation of Socioeconomic Inequalities in Oral Health. European Journal of Public Health, 28, 590-597. https://doi.org/10.1093/eurpub/ckx209

[29] Damaskinos, P., Koletsi-Kounari, H., Economou, C., Eaton, K.A. and Widström, E. (2016) The Healthcare System and Provision of Oral Healthcare in European Union Member States. Part 4: Greece. British Dental Journal, 220, 253-260. https://doi.org/10.1038/sj.bdj.2016.180

[30] Grembowski, D., Spiekerman, C. and Milgrom, P. (2012) Social Gradients in Dental 
Health among Low-Income Mothers and Their Young Children. Journal of Health Care for the Poor and Underserved, 23, 570-588. https://doi.org/10.1353/hpu.2012.0054

[31] Sabbah, W., Tsakos, G., Chandola, T., Sheiham, A. and Watt, R.G. (2007) Social Gradients in Oral and General Health. Journal of Dental Research, 86, 992-996.

[32] Sanders, A.E., Slade, G.D., Turrell, G., John Spencer, A. and Marcenes, W. (2006) The Shape of the Socioeconomic-Oral Health Gradient: Implications for Theoretical Explanations. Community Dentistry and Oral Epidemiology, 34, 310-319. https://doi.org/10.1111/j.1600-0528.2006.00286.x

[33] Enroth, L., Veenstra, M., Aartsen, M., Kjær, A.A., Nilsson, C.J. and Fors, S. (2019) Are There Educational Disparities in Health and Functioning among the Oldest Old? Evidence from the Nordic Countries. European Journal of Ageing, 16, 415-424. https://doi.org/10.1007/s10433-019-00517-x

[34] Allen, P.F. (2003) Assessment of Oral Health Related Quality of Life. Health and Quality of Life Outcomes, 1, Article No. 40, https://doi.org/10.1186/1477-7525-1-40

[35] Locker, D. (1997) Clinical Correlates of Changes in Self-Perceived Oral Health in Older Adults. Community Dentistry and Oral Epidemiology, 25, 199-203. https://doi.org/10.1111/j.1600-0528.1997.tb00926.x

[36] Blaxter, M. (2002) What Is Health? In: Davey, B., Gray, B.A. and Seale, C., Eds., Health and Disease: A Reader, Open University Press, Milton Keynes, 14-34.

[37] Cohen, L.K. and Jago, J.D. (1976) Toward the Formulation of Sociodental Indicators. International Journal of Health Services, 6, 681-698.

[38] Burstrom, B. (2001) Self-Rated Health: Is It as Good a Predictor of Subsequent Mortality among Adults in Lower as Well as in Higher Social Classes? Journal of Epidemiology and Community Health, 55, 836-840. https://doi.org/10.1136/jech.55.11.836

[39] Sun, W., Watanabe, M., Tanimoto, Y., Shibutani, T., Kono, R., Saito, M., Usuda, K. and Kono, K. (2007) Factors Associated with Good Self-Rated Health of Non-Disabled Elderly Living Alone in Japan: A Cross-Sectional Study. BMC Public Health, 7, Article No. 297. https://doi.org/10.1186/1471-2458-7-297

[40] Cott, C.A., Gignac, M.A. and Badley, E.M. (1999) Determinants of Self-Rated Health for Canadians with Chronic Disease and Disability. Journal of Epidemiology and Community Health, 53, 731-736. https://doi.org/10.1136/jech.53.11.731

[41] Marmot, M. (2005) Social Determinants of Health Inequalities. Lancet, 365, 10991104. https://doi.org/10.1016/S0140-6736(05)71146-6

[42] Bartley, M. (2004) Health Inequality: An Introduction to Theories, Concepts and Methods. Polity Press, Cambridge.

[43] Marmot, M. and Wilkinson, R.G. (2001) Psychosocial and Material Pathways in the Relation between Income and Health: A Response to Lynch et al. British Medical Journal, 322, 1233-1236. https://doi.org/10.1136/bmj.322.7296.1233

[44] Locker, D. and Gibson, B. (2005) Discrepancies between Self-Ratings of and Satisfaction with Oral Health in Two Older Adult Populations. Community Dentistry and Oral Epidemiology, 33, 280-288. https://doi.org/10.1111/j.1600-0528.2005.00209.x

[45] Locker, D. (2000) Deprivation and Oral Health. A Review. Community Dentistry and Oral Epidemiology, 28, 161-169. https://doi.org/10.1034/j.1600-0528.2000.280301.x

[46] Adler, N.E., Boyce, T., Chesney, M.A., Cohen, S., Folkman, S., Kahn, R.L. and Syme, 
S.L. (1994) Socioeconomic Status and Health: The Challenge of the Gradient. American Psychologist, 49, 15-24. https://doi.org/10.1037/0003-066X.49.1.15

[47] Adler, N.E. and Snibbe, A.C. (2003) The Role of Psychosocial Processes in Explaining the Gradient between Socioeconomic Status and Health. Current Directions in Psychological Science, 12, 119-123. https://doi.org/10.1111/1467-8721.01245

[48] Damaskinos, P., Koletsi-Kounari, H., Mamai-Homata, E., Margaritis, V. and Papaioannou, W. (2018) Tooth Loss, Cognitive Ability and Socioeconomic Indicators in Older Adults Visiting Day Centers in Athens and Piraeus, Greece. EC Dental Science, 17, 921-931.

[49] World Health Organization (1997) Oral Health Survey: Basic Methods. 4th Edition, World Health Organization, Geneva.

[50] Diener, E., Emmons, R.A., Larsen, R.J. and Griffin, S. (1985) The Satisfaction with Life Scale. Journal of Personality Assessment, 49, 71-75. https://doi.org/10.1207/s15327752jpa4901 13

[51] von dem Knesebeck, O., Verde, P.E. and Dragano, N. (2006) Education and Health in 22 European Countries. Social Science \& Medicine, 63, 1344-1351.

https://doi.org/10.1016/j.socscimed.2006.03.043

[52] ISCO-08. International Standard Classification of Occupation. https://www.ilo.org/public/english/bureau/stat/isco/isco08/index.htm

[53] Adler, N.E. (2000) Relationship of Subjective and Objective Social Status with Psychological and Physiological Functioning: Preliminary Data in Healthy White Women. Health Psychology, 19, 586-592. https://doi.org/10.1037/0278-6133.19.6.586

[54] Greene, J.G. and Vermillion, J.R. (1968) The Simplified Oral Hygiene Index. The Journal of the American Dental Association, 68, 7-13, https://doi.org/10.14219/jada.archive.1964.0034

[55] Adulyanon, S., Vourapukjaru, J. and Sheiham, A. (1966) Oral Impacts Affecting Daily Performance in a Low Dental Disease Thai Population. Community Dentistry and Oral Epidemiology, 24, 385-389. https://doi.org/10.1111/j.1600-0528.1996.tb00884.x

[56] Tsakos, G., Marcenes, W. and Sheiham, A. (2001) Evaluation of a Modified Version of the Index of Oral Impacts on Daily Performances (OIDP) in Elderly Populations in Two European Countries. Gerodontology, 18, 121-130. https://doi.org/10.1111/j.1741-2358.2001.00121.x

[57] Theodosiou, I. and Zangelides, A. (2009) The Social Gradient in Health: The Effect of Absolute Income and Subjective Social Status Assessment on the Individual's Health in Europe. Economic and Human Biology, 7, 229-237.

https://doi.org/10.1016/j.ehb.2009.05.001

[58] Charonis, A., Kyriopoulos, I.I., Spanakis, M., Zavras, D., Athanasakis, K., Pavi, E. and Kyriopoulos, J. (2017) Subjective Social Status, Social Network and Health Disparities: Empirical Evidence from Greece. International Journal for Equity in Health, 16, Article No. 40.

[59] Daniilidou, N., Gregory, S., Zavras, D. and Kyriopoulos, J. (2004) Factors Associated with Self-Rated Health in Greece. A Population-Based Postal Survey. European Journal of Public Health, 14, 209-211. https://doi.org/10.1093/eurpub/14.2.209

[60] Hobdell, M., Sinkford, J., Alexander, C., Alexander, D., Corbet, E., Douglas, C., Katrova, L., Littleton, P., MacCarthy, D., Cherrett, H.M., Schou, L., Wen, F.M. and Zhuan, B. (2002) 5.2 Ethics, Equity and Global Responsibilities in Oral Health and Disease. European Journal of Dental Education, 6, 167-178.

https://doi.org/10.1034/j.1600-0579.6.s3.23.x 
[61] Sanders, A.E., Spencer, A.J. and Slade, G.D. (2006) Evaluating the Role of Dental Behaviour in Oral Health Inequalities. Community Dentistry and Oral Epidemiology, 34, 71-79. https://doi.org/10.1111/j.1600-0528.2006.00261.x

[62] Sanders, A.E., Turrell, G. and Slade, G.D. (2008) Affluent Neighborhoods Reduce Excess Risk of Tooth Loss among the Poor. Journal of Dental Research, 87, 969-973. https://doi.org/10.1177/154405910808701006

[63] Locke, D. and Ford, J. (1996) Using Area-Based Measures of Socioeconomic Status in Dental Health Research. Journal of Public Health Dentistry, 56, 69-75. https://doi.org/10.1111/j.1752-7325.1996.tb02399.x

[64] Locker, D. and Ford, J. (1994) Evaluation of an Area-Based Measure as an Indicator of Inequalities in Oral Health. Community Dental Oral Epidemiology, 22, 80-85. https://doi.org/10.1111/j.1600-0528.1994.tb01577.x

[65] Lang, I.A., Gibbs, S.J., Steel, N. and Melzer, D. (2008) Neighborhood Deprivation and Dental Service Use: A Cross-Sectional Analysis of Older People in England. Journal of Public Health, 30, 472-478. https://doi.org/10.1093/pubmed/fdn047

[66] Morita, I., Nakagaki, H., Yoshii, S., Tsuboi, S., Hayashizaki, J., Mizuno, K. and Sheiham, A. (2007) Is There a Gradient by Job Classification in Dental Status in Japanese Men? European Journal of Oral Sciences, 115, 275-279. https://doi.org/10.1111/j.1600-0722.2007.00455.x

[67] Hong, T., Oddone, E., Weinfurt, K., Friedman, J., Schulman, K. and Bosworth, H. (2004) The Relationship between Perceived Barriers to Healthcare and Self-Rated Health. Psychology, Health \& Medicine, 9, 476-482. https://doi.org/10.1080/13548500412331298966

[68] Farmer, J., Phillips, R.C., Singhal, S. and Quiñonez, C. (2017) Inequalities in Oral Health: Understanding the Contributions of Education and Income. Canadian Journal of Public Health, 14, e240-e245. https://doi.org/10.17269/CJPH.108.5929

[69] De La Hoz, K.F. and Leon, D.A. (1996) Self-Perceived Health Status and Inequalities in Use of Health Services in Spain. International Journal of Epidemiology, 25, 593 603. https://doi.org/10.1093/ije/25.3.593

[70] Hirdes, J.P. and Forbes, W.F. (1993) Factors Associated with the Maintenance of Good Self-Rated Health. Journal of Aging and Health, 5, 101-122. https://doi.org/10.1177/089826439300500105

[71] Dowd, J.B. and Zajacova, A. (2007) Does the Predictive Power of Self-Rated Health for Subsequent Mortality Risk Vary by Socioeconomic Status in the US? International Journal of Epidemiology, 36, 1214-1221. https://doi.org/10.1093/ije/dym214

[72] Idler, E.L. and Angel, R.J. (1990) Self-Rated Health and Mortality in the NHANES-I Epidemiologic Follow-Up Study. American Journal of Public Health, 80, 446-452. https://doi.org/10.2105/AJPH.80.4.446

[73] Song, X.Y., Wu, J., Yu, C.Q., Dong, W.H., Lv, J., Guo, Y., Bian, Z., Yang, L., Chen, Y.P., Chen, Z.M., Pan, A. and Li, L.M. (2009) The Distribution and Correlates of Self-Rated Health in Elderly Chinese: The China Kadoorie Biobank Study. BMC Geriatrics, 19, Article No. 168.

[74] Harschel, A.K., Schaap, L.A., Iwarsson, S., Horstmann, V. and Tomsone, S. (2015) Self-Rated Health among Very Old People in European Countries: An Explorative Study in Latvia and Sweden. Gerontology and Geriatric Medicine, 1, 10 p. https://doi.org/10.1177/2333721415598432

[75] Shibuya, K., Hashimoto, H. and Yano, E. (2002) Individual Income, Income Distribution, and Self-Rated Health in Japan: Cross Sectional Analysis of Nationally Representative Sample. British Medical Journal, 324, Article No. 16. 
https://doi.org/10.1136/bmj.324.7328.16

[76] Bobak, M., Pikhart, H., Hertzman, C., Rose, R. and Marmot, M. (1998) Socioeconomic Factors, Perceived Control and Self-Reported Health in Russia. A Cross-Sectional Survey. Social Science \& Medicine, 47, 269-279.

https://doi.org/10.1016/S0277-9536(98)00095-1

[77] Mejia, G., Armfield, J. and Jamieson, L. (2014) Self-Rated Oral Health and Oral Health-Related Factors: The Role of Social Inequality. Australian Dental Journal, 59, 226-233. https://doi.org/10.1111/adj.12173

[78] Singh, A., Harford, J., Antunes, J.L.F. and Peres M.A. (2018) Area-Level Income Inequality and Oral Health among Australian Adults-A Population-Based Multilevel Study. PLoS ONE, 13, e0191438. https://doi.org/10.1371/journal.pone.0191438

[79] Hakeberg, M. and Wide Boman, U. (2018) Self-Reported Oral and General Health in Relation to Socioeconomic Position. BMC Public Health, 18, Article No. 63.

[80] Jayasvasti, I., Htun, K.C.S.S. and Peltzer, K. (2019) Self-Rated Oral Health Status and Social and Health Determinants among 35-65-Year-Old Persons in One Region in Myanmar: A Cross-Sectional Study. Clinical, Cosmetic and Investigational Dentistry, 11, 339-348. https://doi.org/10.2147/CCIDE.S227957

[81] Barboza-Solís, C., Porras-Chaverri, M. and Fantin, R. (2019) Is Tooth Loss Important When Evaluating Perceived General Health? Findings from a Nationally Representative Study of Costa Rican Adults. Community Dentistry and Oral Epidemiology, 47, 358-365. https://doi.org/10.1111/cdoe.12466

[82] Farmer, J., Mcleod, L., Siddiqi, A., Ravaghi, V. and Quiñonez, C. (2016) Towards an Understanding of the Structural Determinants of Oral Health Inequalities: A Comparative Analysis between Canada and the United States. SSM-Population Health, 2, 226-236. https://doi.org/10.1016/j.ssmph.2016.03.009

[83] Guarnizo-Herreño, C.C., Watt, R.G., Fuller, E., Steele J.G., Shen J., Morris, S., Wildman J. and Tsakos, G. (2014) Socioeconomic Position and Subjective Oral Health: Findings for the Adult Population in England, Wales and Northern Ireland. BMC Public Health, 14, Article No. 827.

[84] Celeste, R.K. and Fritzell, J. (2018) Do Socioeconomic Inequalities in Pain, Psychological Distress and Oral Health Increase or Decrease over the Life Course? Evidence from Sweden over 43 Years of Follow-Up. Journal of Epidemiology and Community Health, 72, 160-167. https://doi.org/10.1136/jech-2017-209123

[85] Benzeval, M., Green, M.J. and Leyland, A.H. (2011) Do Social Inequalities in Health Widen or Converge with Age? Longitudinal Evidence from Three Cohorts in the West of Scotland. BMC Public Health, 11, Article No. 947.

[86] Merlo, J., Gerdtham, U.G., Lynch, J., Beckman, A., Norlund, A. and Lithman, T. (2003) Social Inequalities in Health-Do They Diminish with Age? Revisiting the Question in Sweden 1999. International Journal for Equity in Health, 2, Article No. 2.

[87] Veenstra, G. and Vanzella-Yang, A. (2010) Family Income and Self-Rated Health in Canada: Using Fixed Effects Models to Control for Unobserved Confounders and Investigate Causal Temporality. Social Science \& Medicine, 250, Article ID: 112884. https://doi.org/10.1016/j.socscimed.2020.112884 


\section{Supplementary File-Supplementary Tables}

Table S1. Levels of association for SROH, SRH, SWL and socioeconomic measures in dentate participants $\mathrm{n}=539$ and all participants $\mathrm{N}=743\left(\right.$ Cramer's $\left.^{2}\right)$.

\begin{tabular}{|c|c|c|c|c|c|c|}
\hline & \multicolumn{3}{|c|}{ Dentate participants $(\mathrm{n}=539)$} & \multicolumn{3}{|c|}{ All participants $(\mathrm{N}=743)$} \\
\hline & SROH & SRH & SWL & SROH & SRH & SWL \\
\hline Models & & $p$ & & & $p$ & \\
\hline Long-standing illness & $0.006^{\star *}$ & $<0.001^{\star * *}$ & $<0.001^{\star * *}$ & $<0.001^{\star * *}$ & $<0.001^{* * *}$ & $0.001^{\star \star}$ \\
\hline $\begin{array}{l}\text { Lon-standing illness limited } \\
\text { daily activity }\end{array}$ & $0.008^{\star *}$ & $<0.001^{\star * *}$ & ns & $<0.001^{\star * \star}$ & $<0.001^{\star * \star}$ & $0.029^{*}$ \\
\hline Place of residence & ns & ns & $<0.001^{\star * *}$ & ns & $\mathrm{ns}$ & $<0.001^{\star * *}$ \\
\hline Remaining teeth & $0.001^{* * *}$ & $<0.003^{\star *}$ & ns & $0.003^{* *}$ & $0.003^{* *}$ & $0.008^{* *}$ \\
\hline OHRQOL & $<0.001^{* * *}$ & $0.018^{\star}$ & ns & $<0.001^{\star \star \star *}$ & $0.001^{\star \star}$ & ns \\
\hline Household income & $0.001^{\star * *}$ & $<0.001^{\star * *}$ & $0.022^{*}$ & $0.002^{\star *}$ & $0.009^{\star}$ & $0.001^{\star \star}$ \\
\hline Education & $<0.001^{\star \star \star}$ & $0.002^{\star *}$ & ns & $<0.001^{\star \star \star}$ & $0.002^{* *}$ & ns \\
\hline Occupation & $0.003^{\star *}$ & $0.032^{\star}$ & ns & $0.006^{\star *}$ & $0.023^{*}$ & $0.005^{\star *}$ \\
\hline Subjective social status & $<0.001^{\star * *}$ & $<0.001^{\star * *}$ & $0.001^{\star *}$ & $<0.001^{\star * *}$ & $<0.001^{\star * *}$ & $<0.001^{\star \star *}$ \\
\hline
\end{tabular}

${ }^{\star} p<0.05,{ }^{* *} p<0.01,{ }^{* *} p<0.001 . \mathrm{ns}$ not significant differences.

Table S2. Associations between objective socioeconomic factors and subjective social status predicting SROH and SRH as poor or fair. $\mathrm{N}=743$.

\begin{tabular}{|c|c|c|c|c|c|c|c|c|}
\hline \multirow[b]{3}{*}{ Models } & \multicolumn{7}{|c|}{ All Participants $\mathrm{N}=743$} & \\
\hline & \multicolumn{4}{|c|}{ SROH } & \multicolumn{4}{|c|}{ SRH } \\
\hline & B & OR & $95 \% \mathrm{CI}$ & $p$ & B & OR & $95 \% \mathrm{CI}$ & $p$ \\
\hline $\begin{array}{l}\text { Household income } \\
<800 \text { euro per month }\end{array}$ & -0.448 & 0.639 & $0.443-0.921$ & $0.016^{\star}$ & -0.747 & 0.474 & $0.295-0.760$ & $0.002^{\star *}$ \\
\hline $\begin{array}{l}\text { Education level ISCED-97 } \\
\text { (less than lower secondary) }\end{array}$ & -0.706 & 0.494 & $0.345-0.706$ & $<0.001^{\star * *}$ & -0.400 & 0.670 & $0.466-0.964$ & $0.031^{*}$ \\
\hline Occupation & -0.512 & 0.600 & $0.394-0.913$ & $0.017^{\star}$ & -0.404 & 0.668 & $0.434-1.028$ & ns \\
\hline SSS (low steps 1 - 4) & -0.595 & 0.552 & $0.397-0.766$ & $<0.001^{\star * *}$ & -0.566 & 0.568 & $0.402-0.803$ & $<0.001^{\star * *}$ \\
\hline
\end{tabular}

${ }^{\star} p<0.05,{ }^{* *} p<0.01,{ }^{* *} p<0.001$. Models adjusted for: age, gender, place of residence, living alone, long-standing illness, long-standing illness limited daily activity, loneliness and satisfaction with life.

Table S3. Associations between objective socioeconomic factors and subjective social status predicting SROH and SRH as poor or fair. $\mathrm{N}=539$ (dentate).

\begin{tabular}{|c|c|c|c|c|c|c|c|c|}
\hline \multicolumn{9}{|c|}{ Dentate Participants N = 539} \\
\hline \multirow[b]{2}{*}{ Models } & \multicolumn{4}{|c|}{$\mathrm{SROH}$} & \multicolumn{4}{|c|}{ SRH } \\
\hline & $\mathrm{B}$ & OR & $95 \%$ CI & $p$ & $\mathrm{~B}$ & OR & $95 \% \mathrm{CI}$ & $p$ \\
\hline $\begin{array}{l}\text { Household income } \\
<800 \text { euro per month }\end{array}$ & -0.526 & 0.591 & $0.381-0.916$ & $0.019^{*}$ & -0.747 & 0.474 & $0.295-0.760$ & $0.002^{* *}$ \\
\hline $\begin{array}{l}\text { Education level ISCED-97 } \\
\text { (less than lower secondary) }\end{array}$ & -0.760 & 0.467 & $0.310-0.704$ & $<0.001^{\star * *}$ & -0.502 & 0.605 & $0.396-0.924$ & $0.020^{* *}$ \\
\hline Occupation & -0.655 & 0.519 & $0.322-0.837$ & $0.007^{\star *}$ & -0.452 & 0.637 & $0.389-1.041$ & ns \\
\hline SSS (low steps 1-4) & -0.567 & 0.567 & $0.382-0.841$ & $0.005^{\star *}$ & -0.539 & 0.583 & $0.384-0.885$ & $0.011^{*}$ \\
\hline
\end{tabular}

${ }^{\star} p<0.05,{ }^{\star *} p<0.01,{ }^{* *} p<0.001$. Models adjusted for: age, gender, place of residence, living alone, long-standing illness, long-standing illness limited daily activity, loneliness and satisfaction with life. Education = less than lower secondary education vs lower secondary or above. Occupation = manual workers vs non manual. Subjective social status = low steps $(1-4)$. 